\title{
Características físico-químicas de amidos modificados com permanganato de potássio/ácido lático e hipoclorito de sódio/ácido lático
}

\author{
Physicochemical characteristics of starches modified with potassium \\ permanganate/lactic acid and sodium hypochlorite/lactic acid
}

\author{
Roberto Marques SILVA ${ }^{1}$, Gustavo Fattori FERREIRA ${ }^{1}$, Marianne Ayumi SHIRAI ${ }^{1}$, Ângela HAAS ${ }^{1}$, \\ Melian Luiza SCHERER ${ }^{1}$, Célia Maria Landi FRANCO ${ }^{2}$, Ivo Mottin DEMIATE ${ }^{3 *}$
}

\begin{abstract}
Resumo
Amidos oxidados em elevadas concentrações produzem pastas fluidas, são estáveis à retrogradação e aplicados em indústrias de papel, têxtil e de alimentos. Esta propriedade é atribuída à presença de carboxilas, com cargas negativas e mais volumosas que as hidroxilas. Neste trabalho, amidos de batata, batata doce, mandioca, mandioquinha salsa, milho e milho ceroso foram modificados com $\mathrm{KMnO}_{4} /$ ácido

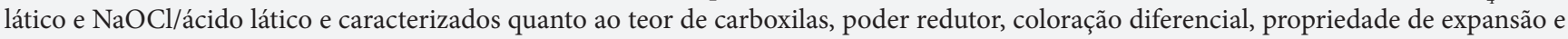
propriedades viscoamilográficas, em água e tampões acetato $(\mathrm{pH} 4,0)$ e fosfato ( $\mathrm{pH} 7,0)$. Amidos de milho ceroso e de mandioca modificados com $\mathrm{KMnO}_{4}$ /ácido lático apresentaram elevadas expansões (25,8 e 24,1 mL.g ${ }^{-1}$, respectivamente). As pastas de amido de milho ceroso resistiram a ciclos de congelamento/descongelamento. A coloração diferencial e o teor de carboxilas não permitiram diferenciar as amostras; apenas o amido de batata reagiu com azul de metileno devido aos grupos fosfato. Quanto ao $\mathrm{pH}$ e acidez, as amostras apresentaram valores próximos da neutralidade, exceto o amido de milho e milho ceroso modificados com $\mathrm{NaOCl}$. Amidos oxidados com $\mathrm{KMnO}_{4} /$ ácido lático apresentaram picos de viscosidade inferiores aos tratados com $\mathrm{NaOCl}$. Os picos de viscosidade em tampão fosfato foram inferiores aos em água e em tampão acetato.
\end{abstract}

Palavras-chave: amidos oxidados; modificação química; expansão; RVA.

\begin{abstract}
Oxidized starches produce low-viscosity pastes even in high concentrations, are stable to retrogradation and are used in the paper, textile and food industries. This property is attributed to the presence of carboxyl groups, which have negative charges and are bulkier than hydroxyls. In this work, potato, sweet potato, Peruvian carrot, cassava, corn and waxy corn starches were modified with oxidative reagents and characterized with respect to their carboxyl content, reducing power, differential dyeing, expansion power and viscographic properties, in water, acetate buffer ( $\mathrm{pH}$ 4.0) and phosphate buffer ( $\mathrm{pH} 7.0$ ). The results showed that waxy corn and cassava starches presented high expansions, when modified with $\mathrm{KMNO}_{4}$ /lactic acid (25.8 and $24.1 \mathrm{~mL} \cdot \mathrm{g}^{-1}$, respectively). The starch pastes of waxy corn showed freeze-thaw stability in all treatments. Differential dyeing and carboxyl content did not vary between the native and modified samples; only potato starch reacted with methylene blue, due to the presence of phosphate groups. With respect to $\mathrm{pH}$ and acidity, almost all samples presented values next to neutrality, except corn and waxy corn starch modified with $\mathrm{NaOCl} /$ lactic acid. The starches oxidized with $\mathrm{KMnO}_{4} / \mathrm{lactic}$ acid presented lower viscosity peaks than those oxidized with $\mathrm{NaOCl}$. The viscosity peaks of starches analyzed in phosphate buffer were lower than in water and acetate buffer. Keywords: oxidized starches; chemical modification; expansion; RVA.
\end{abstract}

\section{Introdução}

O amido é o produto final do processo fotossintético e constitui a principal reserva de carbono das plantas. Sua formação ocorre devido à atividade coordenada de algumas enzimas, tanto nas organelas fotossinteticamente ativas, onde o amido é reserva temporária, quanto nos amiloplastos de órgãos de reserva (CEREDA et al., 2001).

$\mathrm{O}$ amido armazenado nas células de frutos, sementes, raízes e tubérculos se encontra depositado na forma de grânulos mais ou menos brilhantes, apresentando formas e dimensões diversas. Estes grânulos são estruturas semicristalinas, compos- tos de macromoléculas lineares e ramificadas (CEREDA et al., 2001). Os componentes majoritários do amido são a amilose e a amilopectina (BOURSIER, 1994). A amilose é uma molécula essencialmente linear composta por unidades de D-glucose ligadas em alfa (1-4) com pequeno número de ramificações. Já a amilopectina é altamente ramificada e composta por unidades de D-glucose ligadas em alfa (1-4) e com 5 a 6\% de ligações alfa (1-6) nos pontos de ramificação.

Devido ao baixo custo o amido tem sido tradicionalmente utilizado pela indústria como ingrediente calórico e como me-

Recebido para publicação em 14/8/2006

Aceito para publicação em 17/12/2007 (001813)

${ }^{1}$ Bolsistas de Iniciação Científica CNPq e Fundação Araucária, Engenharia de Alimentos, Universidade Estadual de Ponta Grossa, Ponta Grossa - PR, Brasil

${ }^{2}$ Departamento de Engenharia e Tecnologia de Alimentos, Instituto de Biociências, Letras e Ciências Exatas, Universidade Estadual Paulista Júlio de Mesquita Filho,

Rua Cristóvão Colombo, 2265, Jardim Nazareth, CEP 15054-000, São José do Rio Preto - SP, Brasil

3 Departamento de Engenharia de Alimentos, Universidade Estadual de Ponta Grossa, Av. Carlos Cavalcanti, 4748, Bairro Uvaranas, CEP 84030-900, Ponta Grossa - PR,

Brasil,E-mail: demiate@yahoo.com

${ }^{*}$ A quem a correspondência deve ser enviada 
lhorador das propriedades funcionais em sistemas alimentícios. É utilizado para alterar ou controlar diversas características como textura, aparência, umidade, consistência e estabilidade no armazenamento (shelf-life). Pode também ser usado para ligar ou desintegrar; expandir ou adensar; clarear ou tornar opaco; reter a umidade ou inibi-la; produzir textura lisa ou polposa e coberturas leves ou crocantes. Também serve tanto para estabilizar emulsões quanto para formar filmes resistentes ao óleo (CEREDA et al., 2001).

O mercado de amido vem crescendo e se aperfeiçoando nos últimos anos, levando à busca de produtos com características específicas que atendam as exigências industriais (CEREDA; WOSIACKI, 1985; VILPOUX, 1998). Amidos nativos têm sido usados há muito tempo como ingredientes no preparo de diferentes produtos. Entretanto, a utilização de amidos nativos é limitada em função das condições de processamento, como temperatura e $\mathrm{pH}$, que restringem sua aplicação em escala industrial (VAN de BIJ, 1976).

Diante disso, essas limitações podem ser solucionadas com a modificação química, física ou enzimática do amido (VAN de BIJ, 1976). A modificação química dos amidos nativos tem conferido a estes propriedades funcionais peculiares. O grau de modificação dos amidos é produzido por condições controladas de temperatura e $\mathrm{pH}$ e afeta diretamente o preço e a aplicação deste (DOLMATOVA et al., 1998). A possibilidade de introduzir novas matérias-primas agrícolas como fontes de amidos com características interessantes industrialmente, vem suscitando o interesse dos industriais da área, pois proporcionaria um crescimento diferenciado em nível mundial, visto que no Brasil existe uma grande variedade de raízes amiláceas ainda pouco exploradas (VILPOUX, 1998).

A oxidação pode gerar diferentes produtos dependendo dos agentes modificadores utilizados (CEREDA; VILPOUX, 2003; MOORTHY, 1994). Os amidos podem ser oxidados por diversos agentes como o hipoclorito de sódio e de cálcio, o persulfato de amônio, o permanganato de potássio, o peróxido de hidrogênio, o ácido peracético, o cloridrato de sódio e os perboratos e ácidos hipoclóricos (CEREDA; VILPOUX, 2003; SWINKELS, 1996). A modificação por oxidação é produzida pela reação do amido com quantidade específica de reagente em pH e temperatura controladas (KUAKPETIIN; WANG, 2001). A produção desses amidos oxidados baseia-se numa reação com aquecimento de suspensão aquosa de amido em uma solução oxidante. Essa oxidação origina uma pasta branca, fluida e adesiva, que não forma gel rígido após o resfriamento, conservando, para tanto, sua fluidez e natureza adesiva. Diante disso, apesar da possibilidade de utilização na indústria de alimentos, esses amidos são utilizados preferencialmente na indústria de papel, pois produzem suspensões que podem ser usadas como dispersantes, capazes de formar filmes uniformes, os quais selam os poros e proporcionam melhor impressão (CEREDA; VILPOUX, 2003). Essas propriedades são resultados da reação de oxidação, na qual alguns grupos hidroxila das moléculas de amido são primeiramente oxidados a grupos carbonila e, posteriormente, a grupos carboxila. $\mathrm{O}$ número de grupos carbonila e carboxila indicam o grau de oxidação do amido, sendo que esses grupos são originados nas hidroxilas dos carbonos nas posições dois, três e seis. A reação de oxidação do amido é acompanhada de quebra de ligações glicosídicas, com parcial despolimerização do amido (WURZBURG, 1986).

As mudanças de viscosidade em suspensões amiláceas, devido ao intumescimento do grânulo de amido durante o aquecimento são comumente avaliadas em viscoamilógrafos como o Brabender e o Rápido Viscoanalisador (RVA).

A avaliação da viscosidade de amidos feita no aparelho Brabender apresenta uma boa habilidade discriminativa no perfil de empastamento. Entretanto, o longo tempo de análise, a grande quantidade de amostra requerida, a pequena reprodutibilidade de instrumento para instrumento e o difícil procedimento de calibração vêm motivando o uso do RVA, que está se tornando muito popular para análise das propriedades de pasta dos amidos (THOMAS; ATWELL, 1999). O perfil de empastamento de amidos obtidos pelo RVA inclui pico de viscosidade, tempo para atingir este pico, quebra, viscosidade final e temperatura de pasta (THOMAS; ATWELL, 1999), como mostrado na Figura 1.

Durante a fase inicial de aquecimento, um aumento na viscosidade é registrado no RVA quando os grânulos começam a inchar. Neste ponto, polímeros com menor peso molecular, particularmente moléculas de amilose, começam a ser lixiviadas dos grânulos. Um pico de viscosidade é obtido durante o empastamento, quando os grânulos, em sua maioria, estão totalmente inchados, havendo também grânulos intactos e o alinhamento molecular dos polímeros solubilizados ainda não ocorreu dentro do campo de atrito do instrumento. Durante a fase de temperatura $\left(95^{\circ} \mathrm{C}\right)$ e agitação constantes os grânulos começam a quebrar, a solubilização dos polímeros continua e o alinhamento molecular ocorre dentro do campo de atrito do instrumento, causando uma diminuição da viscosidade (THOMAS; ATWELL, 1999).

Ao ocorrer resfriamento, alguns polímeros de amilose e amilopectina solubilizados começam a se reassociar, formando um precipitado ou gel ocorrendo um aumento na opacidade da pasta. Este processo é chamado retrogradação ou setback (WHISTLER;

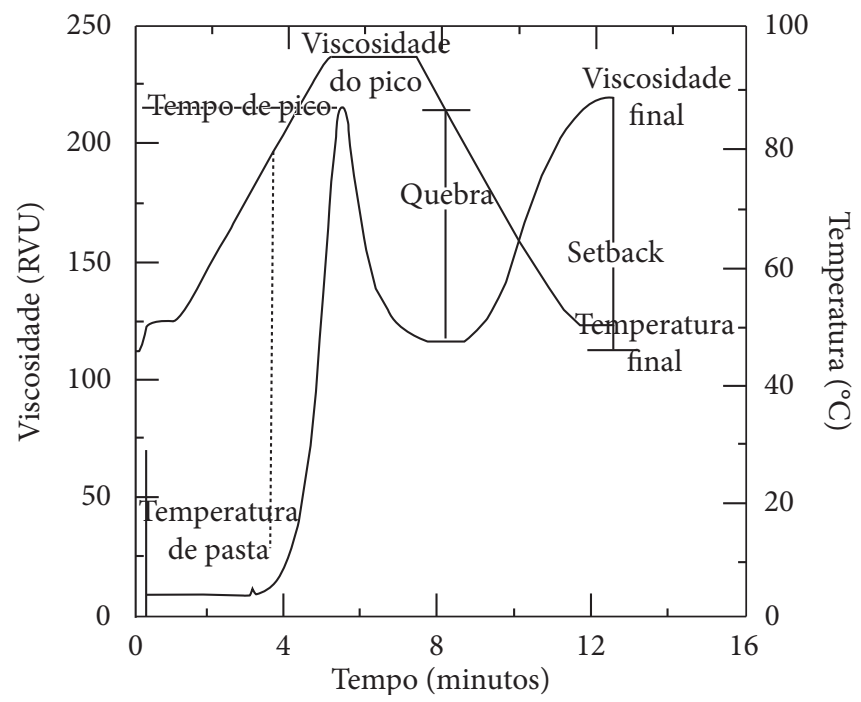

Figura 1. Curva de viscosidade típica do RVA mostrando os parâmetros comumente avaliados. Fonte: Newport Scientific (1998). 
BEMILLER, 1997) e ocorre aumento da viscosidade. Dependendo do tipo de amido (da fonte botânica, ou se é um amido natural ou modificado), do nível de sólidos, do $\mathrm{pH}$ e do regime de aquecimento, vários perfis de gelatinização e empastamento podem ser gerados (THOMAS; ATWELL, 1999).

A retrogradação é basicamente um processo de cristalização das moléculas de amido que ocorre pela forte tendência de formação de pontes de hidrogênio entre moléculas adjacentes. A associação das moléculas do amido propicia o desenvolvimento de uma rede tridimensional mantida coesa pelas áreas cristalinas. Esta rede é formada por grânulos de amido parcialmente inchados e componentes do amido em solução. A formação desta rede durante o resfriamento resulta no aparecimento de gel (HOOVER, 2001). Com o tempo, este gel formado tem a tendência de liberar água. Esta liberação de água é conhecida como sinérese e é comumente encontrada em alguns produtos como molhos em geral (CEREDA et al., 2001).

Devido à retrogradação se potencializar em temperaturas de refrigeração, a sinérese é freqüente em produtos refrigerados e congelados. É importante lembrar que amidos de diferentes fontes botânicas retrogradam em diferentes valores de temperatura (CEREDA et al., 2001).

De acordo com Silva et al. (2006), a análise de resistência a ciclos de congelamento e descongelamento é importante para caracterizar um tipo de amido em termos de sua aplicabilidade em alimentos que devem ser refrigerados e/ou congelados, visto que a liberação de água é geralmente prejudicial à qualidade do produto final.

A característica tecnológica de expansão é verificada em amidos fermentados e secos ao sol ou previamente tratados com ácido lático, secos ao sol ou expostos à radiação UV (NUNES, 1994; NUNES; CEREDA, 1994; VATANASUCHART et al., 2005). O desenvolvimento de féculas de mandioca autoexpansíveis poderá resultar em novos ingredientes para uso na elaboração de biscoitos, pães de queijo e em outros produtos panificáveis livres de glúten (DEMIATE, 1999). O processo fermentativo apenas fragmenta as cadeias amiláceas produzindo ácidos orgânicos, sendo a exposição à luz ultravioleta do sol o tratamento responsável pela propriedade de expansão (CEREDA; LIMA, 1985; CEREDA, 1983a; 1981; DEMIATE, 1999; DEMIATE et al., 1999; DUFOUR et al., 1996; LEONEL; GARCIA; REIS, 2004; MESTRES; ROUAU, 1997; NUNES, 1994; NUNES; CEREDA, 1994; PLATA-OVIEDO; CAMARGO, 1998; 1994). Polvilho azedo foi utilizado em algumas misturas com derivados de soja, obtendo-se um produto panificado de valor nutritivo superior quando comparado com o pão de trigo tradicional (SHEN et al., 1999). A degradação oxidativa do amido de mandioca tem sido associada à propriedade de expansão em diversas publicações (DEMIATE et al., 2005; DEMIATE, 1999; MESTRES; ROUAU, 1997; OOSTEN, 1990).

Os objetivos deste trabalho foram produzir amidos modificados por diferentes tratamentos oxidativos, considerando-se diversas fontes amiláceas, e caracterizar algumas propriedades físico-químicas para auxiliar na compreensão das alterações que ocorrem nos grânulos submetidos a esses tratamentos.

\section{Material e métodos}

As féculas de batata (Solanum tuberosum), batatadoce (Ipomoea batatas) e mandioquinha salsa (Arracacia xanthorrhiza) foram obtidas por processamento em laboratório. Os amidos de milho regular (Zea mays) e a fécula de mandioca (Manihot esculenta) foram adquiridos no comércio local, e o amido de milho ceroso (Zea mays) foi cedido pela empresa Corn Products Brasil (Balsa Nova, Paraná, Brasil).

A produção dos amidos modificados foi feita considerandose resultados de ensaios previamente realizados nos quais a máxima expansão dos amidos, quando empregados na confecção de biscoitos, foi verificada. Em função disso, nas Tabelas 1 e 2 as condições de tempo e temperatura de reação são diferentes.

\subsection{Obtenção dos amidos modificados com permanganato de potássio/ácido lático}

A modificação dos amidos com permanganato de potássio e ácido lático foi feita de acordo com Demiate (1999). Inicialmente foram pesados $250 \mathrm{~g}$ (base úmida) de amido nativo e foram adicionados $750 \mathrm{~g}$ de solução de permanganato de potássio $0,1 \mathrm{~N}$, previamente corrigida para $\mathrm{pH} 3,0$, para atingir $1000 \mathrm{~g}$ de solução. A suspensão foi mantida em banho-maria em tempo e temperatura pré-determinados conforme Tabela 1. As amostras oxidadas foram então recuperadas por filtração em papel qualitativo Whatman $\mathrm{n}^{\circ} 2$ com auxílio de funil de Büchner e lavadas com aproximadamente $2000 \mathrm{~mL}$ de água deionizada para eliminar o excesso de reagentes. O material úmido lavado e filtrado foi transferido para outro recipiente, adicionando-se solução de ácido lático 1\% (p/p) e completando-se o peso para $1000 \mathrm{~g}$ com água deionizada. Procedeu-se a homogeneização da suspensão acidificada, e a temperatura foi ajustada para 25 ou $45^{\circ} \mathrm{C}$ por

Tabela 1. Amostras tratadas com permanganato de potássio $0,1 \mathrm{~N} \mathrm{e}$ ácido lático $1 \%(\mathrm{p} / \mathrm{p})$.

\begin{tabular}{clcc}
\hline Amostra & \multicolumn{1}{c}{ Fonte } & $\begin{array}{c}\text { Tempo de reação } \\
\text { (minutos) }\end{array}$ & $\begin{array}{c}\text { Temperatura } \\
\left({ }^{\circ} \mathrm{C}\right)\end{array}$ \\
\hline 1 & Batata & 30 & 25 \\
2 & Batata doce & 30 & 45 \\
3 & Mandioquinha salsa & 30 & 45 \\
4 & Mandioca & 30 & 25 \\
5 & Milho regular & 60 & 25 \\
6 & Milho ceroso & 30 & 25 \\
\hline
\end{tabular}

Codificação das amostras: $1=$ batper; 2 = badper; $3=$ masper; $4=$ manper; $5=$ mirper e 6 = micper

Tabela 2. Amostras oxidadas com hipoclorito de sódio 0,5\% e ácido lático $1,0 \%(\mathrm{p} / \mathrm{p})$.

\begin{tabular}{rlcc}
\hline Amostra & \multicolumn{1}{c}{ Fonte } & $\begin{array}{c}\text { Tempo de reação } \\
\text { (minutos) }\end{array}$ & $\begin{array}{c}\text { Temperatura } \\
\left({ }^{\circ} \mathrm{C}\right)\end{array}$ \\
\hline 7 & Batata & 60 & 45 \\
8 & Batata doce & 30 & 45 \\
9 & Mandioquinha salsa & 30 & 45 \\
10 & Mandioca & 30 & 45 \\
11 & Milho regular & 60 & 45 \\
12 & Milho ceroso & 60 & 45 \\
\hline
\end{tabular}

Codificação das amostras: 7 = bathip; 8 = badhip; $9=$ maship; $10=$ manhip; $11=$ mirhip e 12 = michip. 
30 ou 60 minutos, conforme Tabela 1, sendo que as amostras foram novamente lavadas e secas em estufa de circulação a $45^{\circ} \mathrm{C}$ por 24 horas. A ordem de adição dos reagentes foi a mesma para todas as fontes amiláceas.

\subsection{Obtenção dos amidos modificados com hipoclorito de sódio/ácido lático}

Foi preparada uma solução de hipoclorito de sódio 0,5\% (p/p) padronizada para $\mathrm{pH} 3,0$. Adicionou-se a $250 \mathrm{~g}$ (base úmida) de amido. A suspensão foi mantida em banho-maria a $45^{\circ} \mathrm{C}$ e o tempo de reação pré-estabelecido de acordo com a Tabela 2. A suspensão foi filtrada em papel de filtro qualitativo (Whatman $\mathrm{n}^{\circ} 2$ ), sendo em seguida lavada com aproximadamente $2000 \mathrm{~mL}$ de água deionizada durante a filtração. Ao material úmido e filtrado adicionou-se solução de ácido lático $1 \%(\mathrm{p} / \mathrm{p})$, e em seguida completou-se o peso para $1000 \mathrm{~g}$ com água deionizada. Homogeneizou-se a suspensão acidificada à temperatura de $45^{\circ} \mathrm{C}$ por 30 ou 60 minutos, conforme Tabela 2 . As amostras foram novamente lavadas e secas em estufa de circulação a $45^{\circ} \mathrm{C}$ por 24 horas.

\subsection{Determinação da propriedade de expansão}

$\mathrm{Na}$ obtenção das massas para avaliação da propriedade de expansão, amostras de $12 \mathrm{~g}$ de amido foram parcialmente gelatinizadas com aproximadamente $10 \mathrm{~mL}$ de água deionizada em ebulição. A quantidade de água variou de acordo com a capacidade de absorção das amostras, sendo definida subjetivamente pela consistência das mesmas. Após a homogeneização manual do amido, a massa foi dividida em três esferas com tamanhos iguais, sendo levadas a um forno elétrico pré-aquecido a $200^{\circ} \mathrm{C}$ e assadas por 30 minutos. Ao final desse período, após resfriarem, as esferas expandidas foram pesadas. Essas esferas foram impermeabilizadas com parafina fundida e seus volumes medidos pelo deslocamento de água em proveta graduada. $\mathrm{O}$ resultado da expansão foi expresso em volume específico, em $\mathrm{mL} \mathrm{g}^{-1}$ (CEREDA, 1983b).

\subsection{Resistência a ciclos de congelamento e descongelamento}

Pastas de amido a $8 \%(\mathrm{p} / \mathrm{p})$ foram aquecidas durante 10 minutos após a gelatinização, e então, armazenadas e congeladas em embalagens plásticas herméticas por um período de 72 horas; após descongelamento a $45^{\circ} \mathrm{C}$ por 3 horas, a quantidade de água liberada foi determinada gravimetricamente e expressa como porcentagem de perda de peso da pasta inicial (TAKIZAWA et al., 2004). O procedimento de congelamento e descongelamento foi repetido uma ou duas vezes para se verificar a liberação de líquido no segundo e terceiro ciclos, respectivamente.

\subsection{Conteúdo de carboxilas}

O teor de carboxilas nas amostras foi determinado por titulação com $\mathrm{NaOH} 0,002 \mathrm{~N}$, empregando-se a fenolftaleína como indicador, conforme descrito por Smith (1967) e empregado por Parovuori et al. (1995). A fim de acidificar todas as carboxilas formadas durante a modificação química, $500 \mathrm{mg}$ de amostra (base seca) foram suspensos em $30 \mathrm{~mL}$ de solução de $\mathrm{HCl} 0,1 \mathrm{~N}$ por 30 minutos, à temperatura ambiente (cerca de $20^{\circ} \mathrm{C}$ ) sob agitação. Após esse período a amostra foi recuperada em cadinho de fundo poroso ( $\left.n^{\circ} 3\right)$ e lavada exaustivamente com água deionizada. $\mathrm{O}$ pH da água de lavagem foi medido para assegurar que estivesse neutro. Esse procedimento foi denominado de desmineralização por Smith (1967). A amostra desmineralizada foi transferida quantitativamente para um erlenmeyer, dispersa em $300 \mathrm{~mL}$ de água deionizada, sendo aquecida até a ebulição com agitação contínua para haver gelatinização do amido. A pasta de amido foi mantida em ebulição por mais 15 minutos para a completa gelatinização. Após esse período, a pasta ainda quente foi titulada com hidróxido de sódio $0,002 \mathrm{~N}$ até a viragem do indicador fenolftaleína. O cálculo da porcentagem de carboxilas no amido foi feito pelo emprego da Equação 1:

$\% \mathrm{COOH}=\mathrm{mL}$ de $\mathrm{NaOH} \times$ normalidade do álcali $\mathrm{x}$

$0,045 \times 100 / g$ amostra seca

\subsection{Determinação de $p H$}

Para determinação do $\mathrm{pH}, 20 \mathrm{~g}$ de amido foram dispersos em $100 \mathrm{~mL}$ de água deionizada e a suspensão agitada por 30 minutos. Cessada a agitação, mediu-se o pH imediatamente, em potenciômetro calibrado, à temperatura ambiente $\left(20^{\circ} \mathrm{C}\right)$ (SMITH, 1967).

\subsection{Acidez}

Para determinação de acidez, $10 \mathrm{~g}$ de amido foram suspensos em $50 \mathrm{~mL}$ de água deionizada e manteve-se a mistura sob agitação por 30 minutos. A amostra foi centrifugada por 2 minutos e $30 \mathrm{~g}$ do sobrenadante foram titulados com $\mathrm{NaOH}$ $0,01 \mathrm{~N}$ na presença de fenolftaleína.

\subsection{Coloração diferencial de grânulos}

Os grânulos dos amidos foram submetidos à coloração diferencial com azul de metileno (CHRISTIANSON et al., 1969; SNYDER, 1984) para observação qualitativa de cargas negativas de grupamentos carboxila. As amostras (cerca de $1 \mathrm{~g}$ ) foram suspensas em $25 \mathrm{~mL}$ de solução de azul de metileno 0,1\% e mantidas sob agitação por 10 minutos. Após esse período as amostras foram exaustivamente lavadas com água deionizada e recuperadas por centrifugação. Foram secas a $45^{\circ} \mathrm{C}$ por 24 horas e observadas em microscópio de luz. Amidos oxidados são aniônicos, o que pode ser demonstrado pela absorção do corante catiônico azul de metileno (WURZBURG, 1986). Os amidos nativos apresentam características de trocadores iônicos ácidos fracos (OOSTEN, 1990). A presença de carboxilas em alguns amidos modificados resulta em diferenças na adsorção do corante catiônico azul de metileno (WURZBURG, 1986).

\subsection{Poder redutor}

Foram pesados $250 \mathrm{mg}$ de amostra, transferindo-os para um erlenmeyer de $250 \mathrm{~mL}$; adicionaram-se $25 \mathrm{~mL}$ de água 
deionizada e a amostra foi gelatinizada, mantendo-se a temperatura de $70{ }^{\circ} \mathrm{C}$ por 5 minutos. Em seguida, foram colocados $25 \mathrm{~mL}$ de ferrocianeto de potássio sob agitação. Manteve-se por 15 minutos em temperatura de ebulição, resfriou-se e foram adicionados $60 \mathrm{~mL}$ da solução de zinco $(200 \mathrm{~mL}$ de ácido acético glacial, $70 \mathrm{~g}$ de $\mathrm{KCl}$ e $20 \mathrm{~g}$ de $\mathrm{ZnSO}_{4}$. $7 \mathrm{H}_{2} \mathrm{O}$ em $1 \mathrm{~L}$ ) e $4 \mathrm{~g}$ de iodeto de potássio, e titulou-se com tiossulfato de sódio. Preparou-se também um branco, sem amostra. Para se calcular o poder redutor, empregou-se a Equação 2 (INTERNATIONAL STARCH INSTITUTE, 2005):

Poder redutor $=(\mathrm{B}-\mathrm{A}) \times 1000 \times \mathrm{N} \times 6,354 / \mathrm{g} \times \mathrm{D}$

$\mathrm{B}=\mathrm{mL}$ de tiossulfato do branco;

$\mathrm{A}=\mathrm{mL}$ de tiossulfato da amostra;

$\mathrm{N}=$ normalidade do tiossulfato;

$\mathrm{g}=$ gramas da amostra; e

$\mathrm{D}=\%$ de matéria seca.

\subsection{Propriedades de pasta}

As propriedades de pasta das seis fontes amiláceas foram determinadas utilizando-se um Rápido Visco-analisador RVA-4 (NEWPORT SCIENTIFIC, 1998), de acordo com procedimento descrito por Franco et al. (2002), com modificações. Os diferentes amidos foram suspensos nos solventes, pesando-se 2,5 g de amido (base seca) e completando para $25 \mathrm{~g}$ (p/p) com água, tampão acetato $0,1 \mathrm{M}(\mathrm{pH} 4,0)$ ou tampão fosfato $0,1 \mathrm{M}(\mathrm{pH} 7,0)$ e colocados, posteriormente, em recipientes de alumínio do equipamento, para a análise. $\mathrm{O}$ equipamento inicia a análise a $50{ }^{\circ} \mathrm{C}$ por 1 minuto; aquece a uma razão de $6{ }^{\circ} \mathrm{C}$ por minuto até atingir $95^{\circ} \mathrm{C}$ e permanece nesta temperatura por 5 minutos; resfria-se até $50{ }^{\circ} \mathrm{C}$ também a $6^{\circ} \mathrm{C}$ por minuto e permanece até o final da análise, que é feita em 23 minutos. Durante toda a análise as suspensões foram agitadas a $160 \mathrm{rpm}$. Foi utilizada a programação Std 2 (Standard analysis 2) do software Thermocline for Windows, versão 2.2 para coleta dos dados e análise dos resultados. Com os dados obtidos foram avaliadas as seguintes características: temperatura de pasta, viscosidade máxima (pico), quebra ou breakdown (diferença entre a viscosidade máxima e da pasta mantida a $95^{\circ} \mathrm{C}$ por 5 minutos), viscosidade final e setback ou tendência à retrogradação (diferença entre as viscosidades final e da pasta a $50{ }^{\circ} \mathrm{C}$ por 5 minutos).

\section{Resultados e discussão}

\subsection{Determinação da propriedade de expansão}

Na Tabela 3 são mostrados os valores de expansão dos amidos modificados.

Os valores obtidos revelaram que o tratamento com permanganato de potássio/ácido lático foi o que gerou amostras modificadas com as maiores expansões, destacando-se os amidos de milho ceroso $\left(25,8 \mathrm{~mL} \mathrm{~g}^{-1}\right)$ e de mandioca $\left(24,1 \mathrm{~mL} \mathrm{~g}^{-1}\right)$. Os valores obtidos de expansão foram maiores que os encontrados por Demiate (1999), que também estudou a oxidação com permanganato de potássio e ácido lático visando a obtenção de féculas de mandioca auto-expansíveis. Takizawa et al. (2004) obtiveram valores de expansão para os amidos nativos de batata, batata doce, mandioquinha salsa, mandioca, milho regular e milho ceroso de 3,1, 2,4, 2,5, 2,2, 1,3 e 8,5 $\mathrm{mL} \mathrm{g}^{-1}$, respectivamente. Amidos com a propriedade de auto-expansão podem ser empregados na produção de pão de queijo e biscoitos, onde essa característica é desejada (NUNES; CEREDA, 1994). Os amidos de mandioca e milho ceroso possuem características que os tornam importantes na produção de snacks (HUANG, 2002; TAKIZAWA et al., 2004).

A propriedade de expansão em amidos também pode ser obtida através da modificação fotoquímica, como estudado por vários autores (NUNES, 1994; NUNES; CEREDA, 1994; PLATA-OVIEDO; CAMARGO, 1994; 1998; VATANASUCHART et al., 2005).

\subsection{Resistência a ciclos de congelamento e descongelamento}

Os resultados referentes ao comportamento das pastas de amido frente a ciclos de congelamento e descongelamento são mostrados na Tabela 4. Os resultados foram expressos em porcentagem de água liberada em relação à massa inicial da pasta.

$\mathrm{O}$ amido de milho ceroso mostrou-se mais resistente aos ciclos de congelamento e descongelamento, não importando o tratamento oxidativo ao qual foi submetido. A maioria das amostras mostrou-se susceptível à liberação de água após o congelamento e descongelamento, principalmente os amidos de mandioca. Takizawa et al. (2004) verificaram que amidos nativos de mandioca e de milho ceroso mostraram-se resistentes a ciclos de congelamento e descongelamento, enquanto que os demais amidos estudados como mandioquinha salsa, batata,

Tabela 3. Expansão dos amidos modificados.

\begin{tabular}{cclc}
\hline Amostra $^{*}$ & $\begin{array}{c}\text { Expansão } \\
\left(\mathrm{mL} \cdot \mathrm{g}^{-1}\right)\end{array}$ & Amostra $^{*}$ & $\begin{array}{c}\text { Expansão } \\
\left(\mathrm{mL} \cdot \mathrm{g}^{-1}\right)\end{array}$ \\
\hline 1 (Batper) & 8,9 & 7 (Bathip) & 3,5 \\
2 (Badper) & 11,7 & 8 (Badhip) & 4,8 \\
3 (Masper) & 10,5 & 9 (Maship) & 6,6 \\
4 (Manper) & 24,1 & 10 (Manhip) & 9,3 \\
5 (Mirper) & 6,4 & 11 (Mirhip) & 11,5 \\
6 (Micper) & 25,8 & 12 (Michip) & 14,9 \\
\hline${ }^{*}$ Consultar as Tabelas 1 e 2 para verificar a codificação das amostras.
\end{tabular}

Tabela 4. Porcentagem de água liberada das pastas após ciclos de congelamento-descongelamento.

\begin{tabular}{cccc}
\hline Amostra & $1^{\circ}$ ciclo & $2^{\circ}$ ciclo & $3^{\circ}$ ciclo \\
\hline 1 (Batper) & 69,3 & 72,1 & 51,6 \\
2 (Badper) & 68,1 & 58,1 & 74,6 \\
3 (Masper) & 69,5 & 73,6 & 52,0 \\
4 (Manper) & 67,1 & 74,3 & 71,6 \\
5 (Mirper) & 56,1 & 68,0 & 67,7 \\
6 (Micper) & 0 & 0 & 0 \\
7 (Bathip) & 50,4 & 61,3 & 57,1 \\
8 (Badhip) & 54,3 & 45,2 & 64,1 \\
9 (Maship) & 45,6 & 62,6 & 62,8 \\
10 (Manhip) & 48,1 & 66,3 & 62,0 \\
11 (Mirhip) & 57,0 & 66,8 & 67,6 \\
12 (Michip) & 0 & 0 & 0 \\
\hline
\end{tabular}


batata doce e milho regular, foram susceptíveis aos ciclos de congelamento e descongelamento, havendo liberação de água de suas pastas.

\subsection{Conteúdo de carboxilas}

O conteúdo de carboxilas das amostras é mostrado na Tabela 5.

Os resultados de carboxilas não permitiram uma clara associação com fonte botânica ou tratamento oxidativo. Devido ao baixo grau de modificação, os valores ficaram muito próximos aos dos amidos nativos, dificultando a visualização dos efeitos dos tratamentos químicos.

O maior conteúdo de carboxilas nos amidos modificados pode ser devido à fragmentação das cadeias amiláceas pelos tratamentos oxidativos (TAKIZAWA et al., 2004). Tanto o conteúdo de carboxilas quanto o grau de degradação das macromoléculas são indicadores da intensidade de oxidação sofrida pelos grânulos de amido (KUAKPETOON; WANG, 2006). Takizawa et al. (2004) obtiveram valores de carboxilas mais elevados para os amidos das mesmas fontes botânicas consideradas no presente estudo, sendo que os teores variaram de $0,16 \%$ para os amidos nativos de milho ceroso e de mandioca até $0,27 \%$ para o amido de batata.

\subsection{Determinação de pH e acidez}

$\mathrm{Na}$ Tabela 6 são mostrados os valores de pH e acidez encontrados para os amidos modificados.

$\mathrm{Na}$ maior parte dos tratamentos os valores de $\mathrm{pH}$ ficaram próximos da neutralidade, exceto para os casos do milho ceroso e do regular tratados com hipoclorito. Os resultados apresentados na Tabela 6 mostram valores de $\mathrm{pH}$ maiores que

Tabela 5. Teor de carboxilas nos amidos modificados.

\begin{tabular}{cclc}
\hline Amostra & Carboxilas (\%) & Amostra & Carboxilas (\%) \\
\hline 1 (Batper) & 0,13 & 7 (Bathip) & 0,16 \\
2 (Badper) & 0,12 & 8 (Badhip) & 0,15 \\
3 (Masper) & 0,18 & 9 (Maship) & 0,10 \\
4 (Manper) & 0,15 & 10 (Manhip) & 0,12 \\
5 (Mirper) & 0,14 & 11 (Mirhip) & 0,17 \\
6 (Micper) & 0,12 & 12 (Michip) & 0,17 \\
\hline
\end{tabular}

Tabela 6. Valores de $\mathrm{pH}$ e acidez dos amidos modificados.

\begin{tabular}{lcc}
\hline Amostra & $\mathrm{pH}$ & $\begin{array}{c}\text { Acidez } \\
(\mathrm{mL} \mathrm{NaOH} 1 \mathrm{~N} / 100 \mathrm{~g} \text { amido })\end{array}$ \\
\hline 1 (Batper) & 6,25 & 0,90 \\
2 (Badper) & 7,23 & 0,44 \\
3 (Masper) & 7,05 & 1,54 \\
4 (Manper) & 7,23 & 0,68 \\
5 (Mirper) & 7,05 & 0,44 \\
6 (Micper) & 7,10 & 0,50 \\
7 (Bathip) & 5,60 & 0,96 \\
8 (Badhip) & 6,71 & 0,46 \\
9 (Maship) & 6,80 & 0,84 \\
10 (Manhip) & 6,85 & 0,60 \\
11 (Mirhip) & 3,79 & 1,62 \\
12 (Michip) & 4,67 & 0,72 \\
\hline
\end{tabular}

os relatados por Takizawa et al. (2004), que encontraram para os amidos nativos de batata, batata doce, mandioquinha salsa, mandioca, milho regular e milho ceroso valores de 5,8, 5,7, 5,3, $5,9,4,9$ e 5,0 , respectivamente.

Os valores de acidez (Tabela 6) variaram de 0,44 a 1,62 mL $\mathrm{NaOH} \mathrm{N} / 100$ g, com destaque para o milho regular modificado com hipoclorito. Valores elevados de acidez podem estar relacionados com a maior presença de carboxilas, porém neste estudo não se encontrou uma correlação entre essas duas variáveis.

\subsection{Coloração diferencial de grânulos}

A avaliação da coloração dos grânulos das amostras mostrou que apenas os amidos de batata apresentaram coloração azul intensa. Isso se deve à presença de grupos fosfato na fécula de batata nativa e não aos tratamentos oxidativos aos quais os amidos foram submetidos. Portanto, em relação a esta coloração não foi possível diferenciar os amidos modificados daqueles nativos, o que possivelmente se deve ao fato de as modificações químicas terem sido muito discretas.

A diferença de adsorção do azul de metileno relaciona-se com a presença de grupos carboxila que aparecem nos amidos modificados. Os grupos carboxila aniônicos, por sua vez, possuem maior afinidade com o azul de metileno do que os protonados (TAKIZAWA et al., 2004). Em relação aos amidos nativos, todos apresentam coloração azul clara exceto o de batata, que tem coloração azul um pouco mais intensa em função da presença de grupos fosfato (TAKIZAWA et al., 2004).

A diferenciação das amostras pela coloração com azul de metileno só é possível para as féculas que contêm teores de carboxila mais elevados, independentemente da propriedade de expansão (DEMIATE, 1999).

\subsection{Poder redutor}

O poder redutor pode indicar o quanto o amido foi degradado pela oxidação. Os amidos de mandioca, milho ceroso e mandioquinha salsa apresentaram os maiores valores de poder redutor de 58,88, 57,02 e 56,17 $\mathrm{mg} \mathrm{Cu} \mathrm{g}^{-1}$ amido, respectivamente, quando modificados com permanganato de potássio/ácido lático. Esses resultados indicam que estes amidos foram mais susceptíveis à modificação. Independentemente da fonte botânica, o grau de modificação para os oxidados com permanganato foi maior do que para os oxidados com hipoclorito.

Os polímeros de glicose são parcialmente degradados com os tratamentos oxidativos, decrescendo o peso molecular e expondo mais os terminais redutores, os quais podem ser oxidados a ácidos carboxílicos (TAKIZAWA et al., 2004).

Silva et al. (2006) ao estudarem o poder redutor de diversos amidos modificados comerciais, verificaram que o maior valor encontrado (116,21 $\mathrm{mg} \mathrm{Cu} \mathrm{g}^{-1}$ amido) foi para uma amostra de dextrina; o segundo maior valor foi encontrado para um amido ácido-modificado (22,43 $\mathrm{mg} \mathrm{Cu} \mathrm{g}^{-1}$ amido). Os valores obtidos na análise de poder redutor estão resumidos na Tabela 7.

Amidos parcialmente degradados como os ácido-modificados e oxidados apresentam valores de poder redutor superiores 
aos dos respectivos amidos nativos (SILVA et al., 2006). Amidos nativos de batata, batata doce, mandioquinha salsa, mandioca, milho regular e milho ceroso apresentaram valores de poder redutor de $0,2,8,5,2,2,7,2,9$ e $8,5 \mathrm{mg} \mathrm{Cu} \mathrm{g}^{-1}$, respectivamente (TAKIZAWA et al., 2004).

\subsection{Propriedade de pasta}

Propriedades de pasta e viscoamilogramas dos amidos em água

Na Tabela 8 são mostrados os principais pontos dos viscoamilogramas dos amidos modificados com permanganato de potássio e ácido lático, ilustrados na Figura 2. Neste caso, os diferentes amidos foram suspensos em água deionizada e analisados no RVA.

Na Tabela 9 são mostrados os principais pontos dos viscoamilogramas dos amidos modificados com hipoclorito de sódio/ácido lático, ilustrados na Figura 3. Neste caso, os diferentes amidos foram suspensos em água deionizada e analisados no RVA.

Propriedades de pasta e viscoamilogramas dos amidos modificados no tampão acetato $(0,1 \mathrm{M}, \mathrm{pH} 4,0)$

$\mathrm{Na}$ Tabela 10 são mostrados os principais pontos dos viscoamilogramas dos amidos modificados com permanganato de potássio e ácido lático, ilustrados na Figura 4. Neste caso, os

Tabela 7. Valores de poder redutor dos amidos modificados.

\begin{tabular}{lclc}
\hline Amostra & $\begin{array}{c}\text { Poder redutor } \\
\left(\mathrm{mg} \mathrm{Cu} \mathrm{g}^{-1} \text { amido }\right)\end{array}$ & \multicolumn{1}{c}{ Amostra } & $\begin{array}{c}\text { Poder redutor } \\
\left(\mathrm{mg} \mathrm{Cu} \mathrm{g}^{-1} \text { amido }\right)\end{array}$ \\
\hline 1 (Batper) & 35,35 & 7 (Bathip) & 4,43 \\
2 (Badper) & 19,00 & 8 (Badhip) & 10,19 \\
3 (Masper) & 56,17 & 9 (Maship) & 22,85 \\
4 (Manper) & 58,88 & 10 (Manhip) & 26,33 \\
5 (Mirper) & 50,46 & 11 (Mirhip) & 22,10 \\
6 (Micper) & 57,02 & 12 (Michip) & 12,14 \\
\hline
\end{tabular}

diferentes amidos foram suspensos em tampão acetato $0,1 \mathrm{M}$ pH 4,0 e analisados no RVA.

Na Tabela 11 são mostrados os principais pontos dos viscoamilogramas dos amidos modificados com hipoclorito de sódio/ ácido lático, ilustrados na Figura 5. Neste caso, os diferentes amidos foram suspensos em tampão acetato $0,1 \mathrm{M}$ com $\mathrm{pH} 4,0$ e analisados no RVA.

Propriedades de pasta e viscoamilogramas dos amidos modificados no tampão fosfato $(0,1 \mathrm{M} \operatorname{com} \mathrm{pH} 7,0)$

Na Tabela 12 são mostrados os principais pontos dos viscoamilogramas dos amidos modificados com permanganato de potássio e ácido lático, ilustrados na Figura 6. Neste caso, os diferentes amidos foram suspensos em tampão fosfato $0,1 \mathrm{M}$ com pH 7,0 e analisados no RVA.

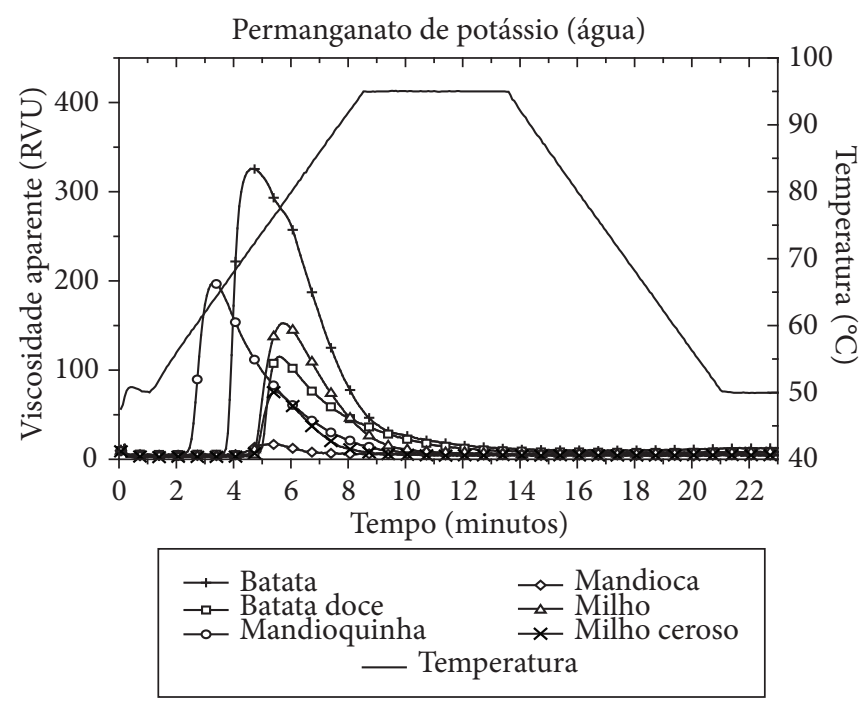

Figura 2. Perfil de viscosidade dos amidos modificados com permanganato de potássio/ácido lático em água.

Tabela 8. Propriedades de pasta dos amidos modificados com permanganato de potássio/ácido lático em água.

\begin{tabular}{lccccc}
\hline \multicolumn{1}{c}{ Amido } & $\begin{array}{c}\text { Temperatura de pasta } \\
\left({ }^{\circ} \mathrm{C}\right)\end{array}$ & $\begin{array}{c}\text { Viscosidade máxima } \\
(\mathrm{RVU})\end{array}$ & $\begin{array}{c}\text { Viscosidade final } \\
(\mathrm{RVU})\end{array}$ & Quebra (RVU) & Setback (RVU) \\
\hline Batata & 66,4 & 326,0 & 12,6 & 316,0 & 3,1 \\
Batata doce & 74,4 & 115,0 & 8,2 & 108,0 & 0,8 \\
Mandioquinha salsa & 59,2 & 198,0 & 5,4 & 194,0 & 13,1 \\
Mandioca & 69,1 & 16,8 & 4,5 & 148,0 & 0,8 \\
Milho & 73,2 & 153,0 & 8,4 & 71,6 & 3,3 \\
Milho ceroso & 72,8 & 75,5 & 4,3 & & 0,5 \\
\hline
\end{tabular}

Tabela 9. Propriedades de pasta dos amidos modificados com hipoclorito de sódio/ácido lático em água.

\begin{tabular}{lcccrr}
\hline \multicolumn{1}{c}{ Amido } & $\begin{array}{c}\text { Temperatura de pasta } \\
\left({ }^{\circ} \mathrm{C}\right)\end{array}$ & $\begin{array}{c}\text { Viscosidade máxima } \\
(\mathrm{RVU})\end{array}$ & $\begin{array}{c}\text { Viscosidade final } \\
(\mathrm{RVU})\end{array}$ & Quebra (RVU) & Setback (RVU) \\
\hline Batata & 68,0 & 46,3 & 22,8 & 33,0 & 9,6 \\
Batata doce & 77,6 & 272,0 & 158,0 & 166,0 & 50,7 \\
Mandioquinha salsa & 60,4 & 417,0 & 49,6 & 385,0 & 16,9 \\
Mandioca & 68,8 & 266,0 & 43,5 & 241,0 & 37,0 \\
Milho & 73,9 & 42,8 & 8,2 & 2,5 & 2,3 \\
Milho ceroso & 71,6 & 4,8 & 2,9 & & 0,7 \\
\hline
\end{tabular}


Na Tabela 13 são mostrados os principais pontos dos viscoamilogramas dos amidos modificados com hipoclorito de sódio/ ácido lático, ilustrados na Figura 7. Neste caso, os diferentes amidos foram suspensos em tampão fosfato $0,1 \mathrm{M}$ com $\mathrm{pH}$ 7,0 e analisados no RVA.

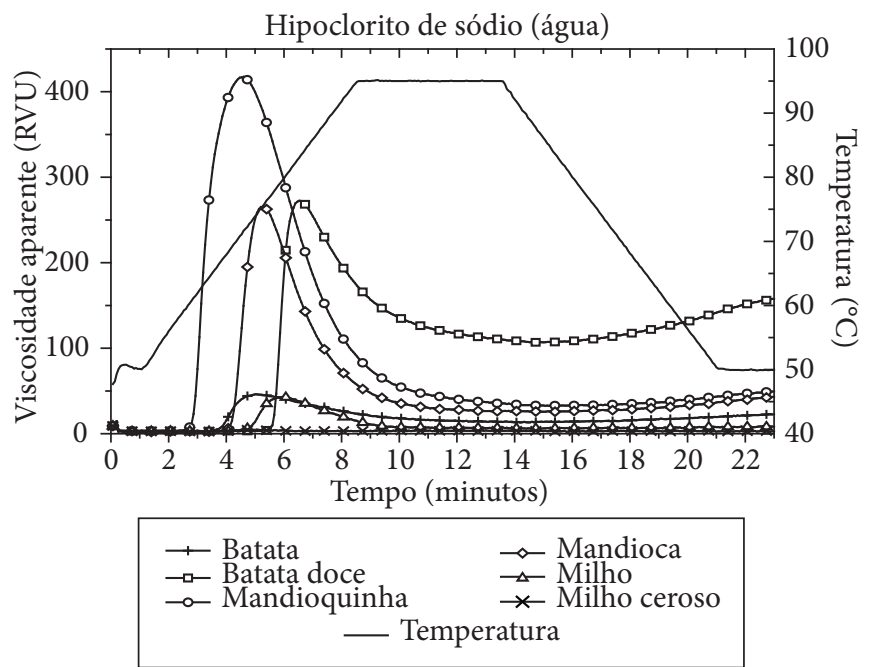

Figura 3. Perfil de viscosidade dos amidos modificados com hipoclorito de sódio/ácido lático, em água.
O emprego de agentes oxidantes, como permanganato de potássio e hipoclorito de sódio, na modificação do amido, confere a este propriedades peculiares. As principais modificações são a oxidação dos grupos redutores a grupos carboxílicos e a formação de grupos carbonila mediante oxidação das hidroxilas e quebra de ligações glucosídicas das cadeias de amido (ABDEL-HAFIZ, 1995). A oxidação ocorre principalmente na lamela amorfa dos anéis semicristalinos do grão de amido. Essa região consiste basicamente de amilose rodeada de amilopectina. Diante disso, a amilose é mais susceptível à oxidação devido a essa cadeia ser mais acessível, em regiões amorfas dos grânulos (KUAKPETOON; WANG, 2006; WANG; WANG, 2003).

O tratamento dos amidos com permanganato de potássio/ ácido lático como agente oxidante proporcionou modificação mais intensa dos amidos quando comparado com o tratamento com hipoclorito de sódio, visto que o primeiro proporcionou ao amido menores picos de viscosidade (TAKIZAWA et al., 2004; WANG; WANG, 2003).

A viscosidade aparente dos amidos das diferentes matérias-primas amiláceas é menor se comparada com os amidos nativos que não sofreram processo de modificação por agentes oxidantes ${ }^{1}$. Isto se deve ao fato da oxidação reduzir o tamanho das cadeias que compõem o amido. Takizawa et al. (2004) encontraram valores de viscosidade máxima para os amidos de batata, batata doce, mandioquinha salsa, mandioca, milho

Tabela 10. Propriedades de pasta dos amidos modificados em permanganato de potássio/ácido lático em tampão acetato com pH 4,0.

\begin{tabular}{lccccc}
\hline \multicolumn{1}{c}{ Amido } & $\begin{array}{c}\text { Temperatura de pasta } \\
\left({ }^{\circ} \mathrm{C}\right)\end{array}$ & $\begin{array}{c}\text { Viscosidade máxima } \\
(\mathrm{RVU})\end{array}$ & $\begin{array}{c}\text { Viscosidade final } \\
(\mathrm{RVU})\end{array}$ & Quebra (RVU) & $\begin{array}{c}\text { Setback (RVU) } \\
\text { Batata }\end{array}$ \\
Batata doce & 66,9 & 424,0 & 13,3 & 415,0 & 4,3 \\
Mandioquinha salsa & 74,8 & 190,0 & 8,0 & 184,0 & 2,3 \\
Mandioca & 60,0 & 263,0 & 3,1 & 262,0 & 1,8 \\
Milho & 73,5 & 78,7 & 11,0 & 197,0 & 7,3 \\
Milho ceroso & 72,4 & 203,0 & 2,6 & 205,0 & 1,3 \\
\hline
\end{tabular}

Tabela 11. Propriedades de pasta dos amidos modificados com hipoclorito de sódio/ácido lático, em tampão acetato com pH 4,0.

\begin{tabular}{lcccrr}
\hline \multicolumn{1}{c}{ Amido } & $\begin{array}{c}\text { Temperatura de pasta } \\
\left({ }^{\circ} \mathrm{C}\right)\end{array}$ & $\begin{array}{c}\text { Viscosidade máxima } \\
(\mathrm{RVU})\end{array}$ & $\begin{array}{c}\text { Viscosidade final } \\
(\mathrm{RVU})\end{array}$ & Quebra (RVU) & Setback (RVU) \\
\hline Batata & 67,5 & 39,3 & 17,8 & 28,3 & 6,8 \\
Batata doce & 78,4 & 269,0 & 147,0 & 175,0 & 52,5 \\
Mandioquinha salsa & 60,8 & 405,0 & 40,1 & 379,0 & 14,5 \\
Mandioca & 69,6 & 251,0 & 37,0 & 229,0 & 29,0 \\
Milho & 74,4 & 32,4 & 5,8 & 1,0 & 2,3 \\
Milho ceroso & 72,4 & 2,2 & 1,1 & 0,6 \\
\hline
\end{tabular}

Tabela 12. Propriedades de pasta dos amidos modificados em permanganato de potássio/ácido lático, em tampão fosfato com pH 7,0.

\begin{tabular}{lccccc}
\hline \multicolumn{1}{c}{ Amido } & $\begin{array}{c}\text { Temperatura de pasta } \\
\left({ }^{\circ} \mathrm{C}\right)\end{array}$ & $\begin{array}{c}\text { Viscosidade máxima } \\
(\mathrm{RVU})\end{array}$ & $\begin{array}{c}\text { Viscosidade final } \\
(\mathrm{RVU})\end{array}$ & Quebra (RVU) & Setback (RVU) \\
\hline Batata & 66,0 & 86,4 & 3,2 & 84,3 & 1,0 \\
Batata doce & 75,9 & 51,8 & 2,8 & 50,3 & 1,3 \\
Mandioquinha salsa & 59,3 & 67,5 & 1,6 & 66,6 & 0,3 \\
Mandioca & 66,8 & 3,25 & 1,1 & 4,58 & 0,4 \\
Milho & 75,2 & 50,4 & 4,5 & 47,8 & 1,8 \\
Milho ceroso & 70,4 & 6,58 & 2,1 & 5,5 & 1,0 \\
\hline
\end{tabular}


Tabela 13. Propriedades de pasta dos amidos modificados com hipoclorito de sódio/ácido lático, em tampão fosfato com pH 7,0.

\begin{tabular}{|c|c|c|c|c|c|}
\hline Amido & $\begin{array}{c}\text { Temperatura de pasta } \\
\left({ }^{\circ} \mathrm{C}\right)\end{array}$ & $\begin{array}{l}\text { Viscosidade máxima } \\
\text { (RVU) }\end{array}$ & $\begin{array}{c}\text { Viscosidade final } \\
\text { (RVU) }\end{array}$ & Quebra (RVU) & Setback (RVU) \\
\hline Batata & 68,4 & 28,3 & 7,8 & 23,3 & 2,9 \\
\hline Batata doce & 81,1 & 145,0 & 49,2 & 112 & 17,1 \\
\hline Mandioquinha salsa & 60,8 & 120,0 & 6,9 & 115 & 2,6 \\
\hline Mandioca & 70,7 & 29,0 & 4,7 & 27,0 & 2,7 \\
\hline Milho & 76,3 & 6,0 & 2,1 & 5,3 & 1,3 \\
\hline Milho ceroso & 74,8 & 1,75 & 1,3 & 1,42 & 1,0 \\
\hline
\end{tabular}

Permanganato de potássio (tampão-acetato $\mathrm{pH}=4,0$ )

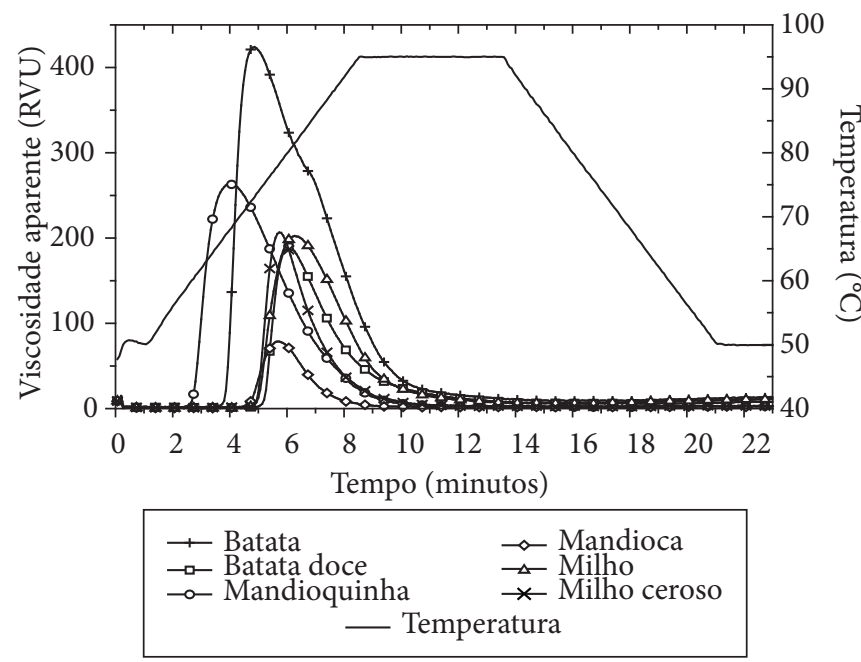

Figura 4. Perfil de viscosidade dos amidos modificados com permanganato de potássio/ácido lático, em tampão acetato com $\mathrm{pH} 4,0$.

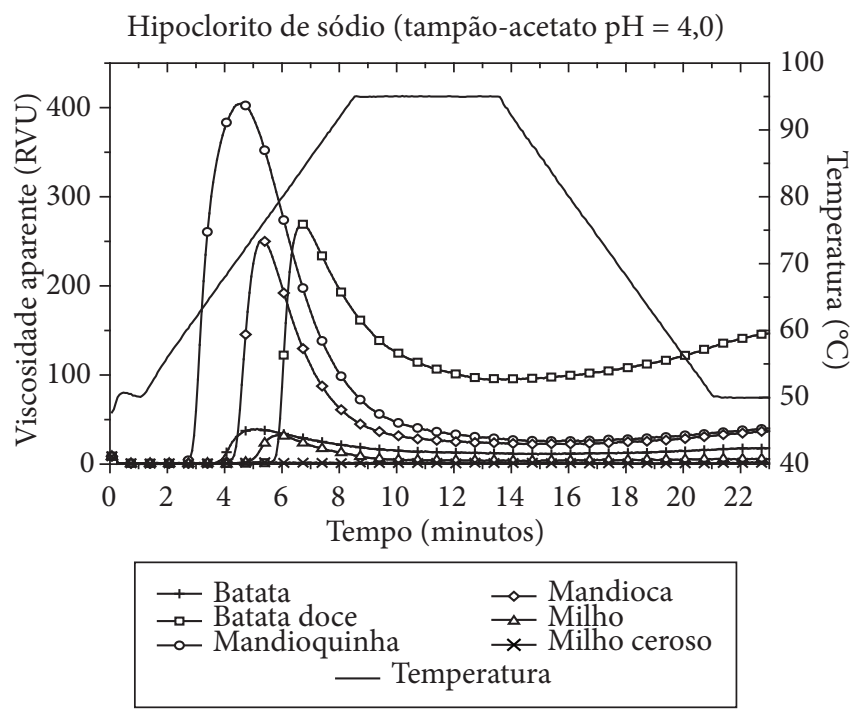

Figura 5. Perfil de viscosidade dos amidos modificados com hipoclorito de sódio/ácido lático, em tampão acetato com pH 4,0.

regular e milho ceroso de 750, 250, 280, 250, 160 e 220 RVU, respectivamente, quando analisados em água.

Verificando-se as Figuras 2 a 7 e as Tabelas 8 a 13, fica evidente que o solvente no qual o amido foi suspenso influencia diretamente o comportamento viscoamilográfico. Ao se anali-
Permanganato de potássio (tampão-fosfato $\mathrm{pH}=7,0$ )
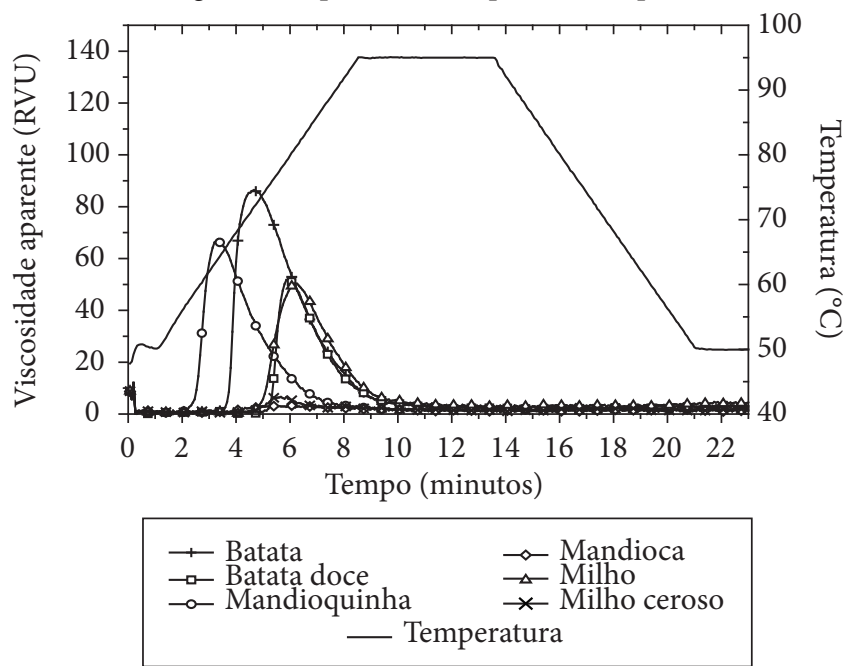

Figura 6. Perfil de viscosidade dos amidos modificados com permanganato de potássio/ácido lático, em tampão fosfato com pH 7,0.

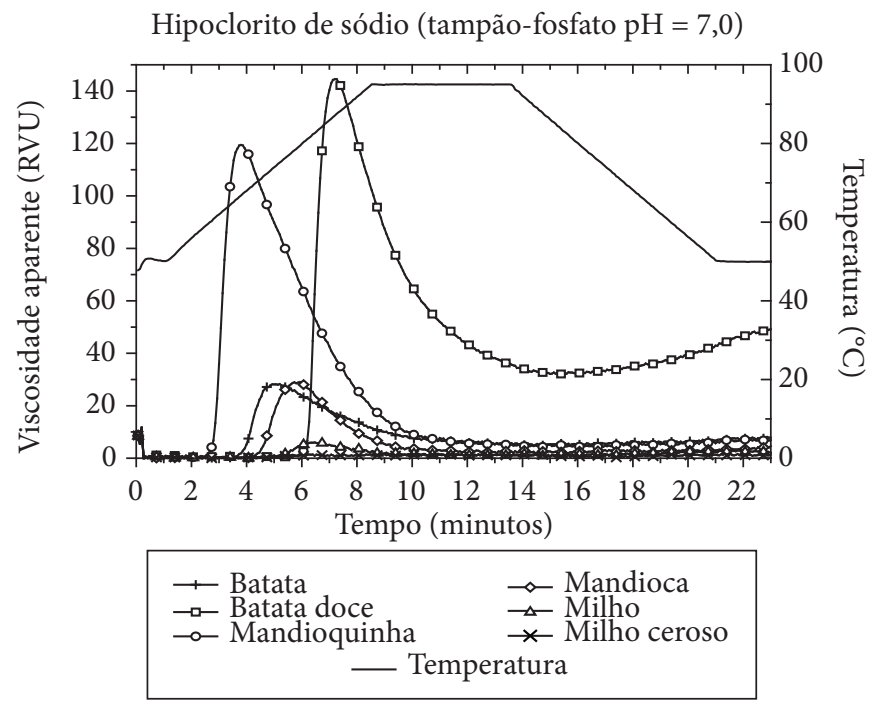

Figura 7. Perfil de viscosidade dos amidos modificados com hipoclorito de sódio/ácido lático, em tampão fosfato com pH 7,0.

sar os valores de viscosidade máxima nos diferentes solventes, verificou-se que em água e em tampão acetato com pH 4,0 foram maiores que em tampão fosfato com pH 7,0. Apesar das amostras apresentarem menores picos de viscosidade e instabilidade ao cozimento em todos os solventes, a medida que o $\mathrm{pH}$ 
aumenta os picos de viscosidade diminuem (DEMIATE et al., 2005). Em pH 7,0, em alguns casos, não é possível detectar qualquer viscosidade durante a análise, pois a pasta de amido mostra-se muito fluida. Devido ao aparecimento de cargas negativas (carboxilas), o amido torna-se um polieletrólito em $\mathrm{pH}$ mais elevado, e devido a interações entre as cargas o amido torna-se menos viscoso.

Comparando os picos de viscosidade, setback e quebra dos amidos modificados com hipoclorito de sódio em todos os solventes, verifica-se de uma maneira geral, que esses apresentam maior valor que os amidos modificados com permanganato de potássio/ácido lático. Dentre as matérias-primas amiláceas analisadas, o amido de milho ceroso e o amido de mandioca foram as mais susceptíveis à oxidação, pois apresentaram menores picos de viscosidade e maior instabilidade ao cozimento, resultando em pastas mais fluidas. A elevada capacidade de expansão de amidos de mandioca já foi associada a baixos valores de picos de viscosidade e também de viscosidade intrínseca (DEMIATE et al., 2005; MESTRES; ROUAU, 1997).

É importante salientar que praticamente todos os amidos apresentaram baixos valores de viscosidade a $50{ }^{\circ} \mathrm{C}$ (retrogradação). Essas características dos amidos modificados por oxidação são associadas à presença de grupamentos carbonila e carboxila que dificultam a reassociação das cadeias de amido para a formação do gel novamente (ADEBOWALE; AFOLABI; LAWAL, 2002; LEONEL; GARCIA; REIS, 2004).

$\mathrm{O}$ amido de batata doce modificado com hipoclorito de sódio foi o que apresentou maior tendência à retrogradação, sendo indicativo de que esse amido foi menos susceptível à oxidação promovida pelo hipoclorito. $\mathrm{O}$ amido de mandioquinha salsa teve um comportamento diferenciado dos demais amidos porque apresentou pico de viscosidade elevado em todos os solventes, tanto no tratamento com permanganato de potássio/ ácido lático quanto com hipoclorito de sódio. Resultados parecidos foram relatados por Takizawa et al. (2004). Os amidos de batata-doce, mandioquinha salsa e batata apresentaram picos agudos e alta quebra de viscosidade, o que revela a fragilidade dos grânulos desses amidos quando cozidos em água (VIEIRA, 1994). O amido de batata modificado com hipoclorito de sódio, por sua vez, apresentou pico de viscosidade e setback inferiores àqueles observados quando este foi modificado com permanganato de potássio/ácido lático, sendo um comportamento distinto em relação aos outros amidos.

$\mathrm{O}$ amido de mandioquinha salsa também se destacou em relação aos outros amidos por ter sido o que apresentou as menores temperaturas de gelatinização, muito próximas de $60^{\circ} \mathrm{C}$, durante a análise viscoamilográfica.

\section{Conclusões}

Os amidos modificados apresentaram diferenças nas características avaliadas, com destaque para o amido de mandioca e para o amido de milho ceroso, que apresentaram valores elevados de expansão. A análise de carboxilas não revelou uma relação clara entre tratamento oxidativo e fonte botânica, pois os resultados obtidos foram próximos entre si. A oxidação também proporcionou maiores valores de poder redutor e maior susceptibilidade à sinérese, quando avaliada por intermédio da liberação de líquido durante ciclos de congelamento e descongelamento.

Os amidos modificados por agentes oxidantes adquirem características que possibilitam sua utilização em diversos tipos de indústrias. Constatou-se que os amidos oxidados estudados apresentam baixos picos de viscosidade, pois a modificação química à qual foram submetidos promoveu redução do peso molecular além do surgimento de grupos carbonila e carboxila, resultantes da oxidação de hidroxilas. Verificou-se que os amidos foram mais intensamente modificados com o tratamento com permanganato de potássio/ácido lático do que com hipoclorito de sódio, pois os picos de viscosidade foram maiores para os amidos tratados com este último reagente. Conclui-se que o perfil viscoamilográfico varia com o $\mathrm{pH}$ do solvente no qual a pasta é produzida, o que sugere a presença de carboxilas com cargas na estrutura das macromoléculas constituintes do amido. Além disso, observando-se os viscoamilogramas, houve diferentes comportamentos dos amidos das matérias-primas em relação aos tratamentos químicos empregados.

\section{Agradecimentos}

Os autores agradecem ao Conselho Nacional de Desenvolvimento Científico e Tecnológico (CNPq), à Fundação Araucária pelo apoio financeiro e à Corn Products Brasil pela doação do amido de milho ceroso.

\section{Referências bibliográficas}

ABDEL-HAFIZ, S. A. Accelerated oxidation of maize starch using the sodium chlorite/thiourea system. Polymer Degradation and Stability, Oxford, v. 47, n. 2, p. 275-281, 1995.

ADEBOWALE, K. O.; AFOLABI, T. A.; LAWAL, O. S. Isolation, chemical modification and physicochemical characterization of Bambarra groundnut (Voandzeia subterranean) starch and flour. Food Chemistry, Oxford, v. 78, n. 3, p. 305-311, 2002.

BOURSIER, B. Applications alimentaires des amidons modifiés. Industries Alimentaires et Agricoles, Paris, v. 111, n. 9, p. 583-592, 1994.

CEREDA, M. P. et al. Propriedades gerais do amido. São Paulo, Fundação Cargill, 221 p. (Série: Culturas de tuberosas amiláceas Latino-americanas, v. 1) 2001.

CEREDA, M. P.; LIMA, U. A. Aspectos sobre fermentação da fécula de mandioca III. Determinação dos ácidos orgânicos. Turrialba, San José, v. 35, n. 1, p. 19-24, 1985.

CEREDA, M. P. Avaliação da qualidade de duas amostras de fécula fermentada de mandioca (polvilho azedo). Boletim da Sociedade Brasileira de Ciência e Tecnologia de Alimentos, Campinas, v. 17, n. 3, p. 305-320, 1983a.

Estudos físico-químicos e microbianos da esterilização e da fermentação da fécula da mandioca. Dissertação (Mestrado em Ciência e Tecnologia de Alimentos) Faculdade de Ciências Agronômicas, Campus de Botucatu, Universidade Estadual Paulista "Júlio de Mesquita Filho" (UNESP), Botucatu, 1981, 155 p.

. Padronização de qualidade de fécula de mandioca fermentada (polvilho azedo) I. Formulação e preparo de biscoitos. Boletim da Sociedade Brasileira de Ciência e Tecnologia de Alimentos, Campinas v. 17, n. 3, p. 287-95, 1983 b. 
CEREDA, M. P.; VILPOUX, O. F. Tecnologia, usos e potencialidades de tuberosas amiláceas Latino Americanas. São Paulo: Fundação Cargill, 711p. (Culturas de Tuberosas Amiláceas Latino Americanas v.3) 2003.

CEREDA, M. P.; WOSIACKI, G. Characterization of Pinhão Starch. Part I. Extraction and Properties of the Starch Granules. Starch/ Stärke, Weinheim, v. 37, p. 224-227, 1985.

CHRISTIANSON, D. D. et al. Isolation and chemical composition of protein bodies and native proteins in corn endosperm. Cereal Chemistry, Saint Paul, v. 46, p. 372-381, 1969.

DEMIATE, I. M. et al. Viscographic characteristics of oxidized cassava starches assessed by RVA. Publicatio UEPG - Ciências exatas e da terra, ciências agrárias e engenharias, Ponta Grossa, v. 11, n. 1, p. 07-17, 2005.

DEMIATE, I. M. Desenvolvimento de fécula de mandioca autoexpansível. Dissertação (Mestrado em Ciência e Tecnologia de Alimentos) Faculdade de Ciências Agronômicas, Campus de Botucatu, Universidade Estadual Paulista "Júlio de Mesquita Filho" (UNESP), Botucatu, 1999. 149 p.

DEMIATE, I. M. et al. Organic acid profile of commercial sour cassava starch. Ciência e Tecnologia de Alimentos, Campinas, v. 19, n. 1, p. 131-135, 1999.

DOLMATOVA, L. et al. Identification of modified starch using infrared spectroscopy and artificial neural network processing. Society for Applied Spectroscopy, Frederick, v. 52, n. 3, p. 329-338, 1998.

DUFOUR, D. et al. Improving the bread-making potential of cassava sour starch. In: DUFOUR, D.; O’BRIAN, G. M.; BEST, R. (Ed.) Processing Meeting on Cassava Flour and Starch. Progress in Research and Development, CIRAD/CIAD, Cali, 1996. p. 133-142.

FRANCO, C. M. L. et al. Structural and functional characteristics of selected soft wheat starches. Cereal Chemistry, Saint Paul, v. 79, p. 243-248, 2002.

HOOVER, R. Composition, molecular structure and physicochemical properties of tuber and root starches: a Review. Carbohydrate Polymers, Oxford, v. 45, n. 3, p. 253-267, 2001.

HUANG, D. P. New perspectives on starch and starch derivatives for snack applications. National Starch and chemical company, 2000. Disponível em: <www.foodstarch.com/products_services/pdfs/ newpersp.pdf $>$. Acesso em: 18 maio 2002.

INTERNATIONAL STARCH INSTITUTE. Determination of reductive power in starch. Disponível em: $<$ http://home3.inet.tele. dk./starch/isi/methods 35rcu.htm.>. Acesso em: 03 maio 2005.

KUAKPETOON, D.; WANG, Y. J. Characterization of Different Starches Oxidized by Hypochlorite. Starch/ Stärke, Weinheim, v. 53, n. 5, p. 211-218, 2001.

. Structural characteristics and physicochemical properties of oxidized corn starches varying in amylose content. Carbohydrate Research, Oxford, v. 341, n. 11, p. 1896-1915, 2006.

LEONEL, M.; GARCIA, A. C. B.; REIS, M. M. Caracterização físicoquímica e microscópica de amidos de batata-doce, biri, mandioca e taioba e propriedades de expansão após modificação fotoquímica. Brazilian Journal of Food Technology, Campinas, v. 7, n. 2, p. 129-137, 2004.

MESTRES, C.; ROUAU, X. Influence of natural fermentation and druing conditions on the physico-chemical characteristics of cassava starch. Journal of the Science of Food and Agriculture, London, v. 74, n. 2, p. 147-155, 1997.
MOORTHY, S. N. Tuber crop starches. Thiruvananthapuram: Central Tuber Crops Research Institute (Technical Bulletin Series, v. 18), 1994. $40 \mathrm{p}$.

NEWPORT SCIENTIFIC. Instruction Manual for the Series 4 Rapid Visco Analyzer. Newport Scientific Pty. Ltd., Australia, 1998.

NUNES, O. L. G. S. Efeito da radiação ultravioleta sobre as propriedades funcionais da fécula de mandioca tratada com ácido lático, Dissertação (Mestrado em Ciência e Tecnologia de Alimentos) Faculdade de Ciências Agronômicas, Campus de Botucatu, Universidade Estadual Paulista "Júlio de Mesquita Filho" (UNESP), 1994. $156 \mathrm{p}$.

NUNES, O. L. G. S.; CEREDA, M. P. Effect of druing processes on the developement of expansion in cassava starch hydrolyzed by lactic acid. In: International Meeting on Cassava Flour and Starch, p.110, January 11-15, 1994. Cali/CIAT, Cali, Colômbia.

OOSTEN, B. J. Interactions between starch and electrolytes. Starch/ Stärke, Weinheim, v. 42, n. 9, p. 327-330, 1990.

PAROVUORI, P. et al. Oxidation of potato starch by hydrogen peroxide. Starch/Stärke, Weinheim, v. 47, n. 1, p. 19-23, 1995.

PLATA-OVIEDO, M.; CAMARGO, C. Effect of acid treatments and drying processes on physico-chemical and functional properties of cassava starch. Journal of the Science Food and Agriculture, London, v. 77, n. 1, p. 103-108, 1998.

Sun-dried sour cassava starch: expansion property. In: International Meeting on Cassava Flour and Starch, January 11-15, 1994. Cali/CIAT, Cali, Colômbia. p. 110.

SÁNCHEZ-RIVERA, M. M. et al. Partial characterization of banana starches oxidized by different levels of sodium hypochlorite. Carbohydrate Polymers, Oxford, v. 62, n. 1, p. 50-56, 2005.

SHEN, $H$. et al. Applying cassava sour food starch in bread making. Zhongguo Liangyou Xuebao, v. 13, n. 6, p. 19-20, 1998. Disponível em: <http://stneasy.cas.org/tmp/437-0399235608-200/514298937. htm> Acesso em: 25 abr. 1999.

SILVA, G. O. et al. Características físico-químicas de amidos modificados de grau alimentício comercializados no Brasil. Ciência e Tecnologia de Alimentos, Campinas, v. 26, n. 1, p. 188-197, 2006.

SMITH, R. J. Characterization and analysis of starches. In: WHISTLER, R. L.; PASCHALL, E. F. Starch: Chemistry and Technology. New York: Academic Press, 1967, v. 2, p.569-635.

SNYDER, E. M. Industrial microscopy of starches. In: WHISTLER, R. L., BEMILLER, J. N., PASCHALL, E. F. Starch: Chemistry and Technology, 2nd edition, New York: Academic Press, 1984. v. 2. p. 575-591.

SWINKELS, J. J. M. Industrial starch chemistry: Properties, modifications and applications of starches. Veendam: AVEBE, 1996. 48 p.

TAKIZAWA, F. F. et al. Characterization of tropical starches modified with potassium permanganate and lactic acid. Brazilian Archives of Biology and Technology, Curitiba, v. 47, n. 6, p. 921-931, 2004.

THOMAS, D. J.; ATWELL, W. A. Practical Guide for Food Industry In: Starches. Minnesota: Eagan Press, 1999. 30 p.

VAN de BIJ, J. The analysis of starch derivaties. Examination and analysis of starch. London: Applied Science Publisher, 1976. $189 \mathrm{p}$.

VATANASUCHART, N. et al. Molecular properties of cassava starch modified with different UV irradiations to enhance baking expansion. Carbohydrate Polymers, Oxford, v. 61, n. 1, p. 80-87, 2005. 
VIEIRA, F. C. Efeito do tratamento com calor e baixa umidade sobre características físicas e funcionais dos amidos de mandioquinha-salsa (Arracacia xanthorrhiza), de batata-doce (Ipomoea batatas) e de gengibre (Zingiber officinale). Dissertação (Mestrado em Ciência e Tecnologia de Alimentos), Faculdade de Ciências Agronômicas, Campus de Piracicaba, Escola Superior de Agricultura "Luiz de Queiroz" (ESALQ), Piracicaba, 1994. 94 p.

VILPOUX, O. Amidos adaptados ao uso nas indústrias de alimentos. Fax/Jornal CERAT/UNESP, Botucatu, n. 70, p. 1-2, 1998.
WANG, Y.; WANG, L. Physicochemical properties of common and waxy corn starches oxidized by different levels of sodium hypochlorite. Carbohydrate Polymers, Oxford, v. 52, p. 207-217, 2003.

WHISTLER, R. L.; BEMILLER, J. N. Starch. In: Carbohydrate Chemistry for Food Scientists. Saint Paul: AACC, Eagan Press, 1997. p. 117-151.

WURZBURG, O. B. Converted starches. In: Wurzburg, O. B. Modified starches: Properties and uses. Boca Raton, FL: CRC Press, 1986. 